\title{
Marie-Claire Blais, L'esiliato seguito da I viaggiatori sacri
}

\section{Veronica Cappellari}

\section{(2) OpenEdition}

1 Journals

\section{Edizione digitale}

URL: http://journals.openedition.org/studifrancesi/9071

DOI: 10.4000/studifrancesi.9071

ISSN: 2421-5856

\section{Editore}

Rosenberg \& Sellier

\section{Edizione cartacea}

Data di pubblicazione: 1 octobre 2008

Paginazione: 502-503

ISSN: 0039-2944

\section{Notizia bibliografica digitale}

Veronica Cappellari, «Marie-Claire Blais, L'esiliato seguito da I viaggiatori sacri», Studi Francesi [Online] 155 (LII | II) | 2008, online dal 30 novembre 2015, consultato il 13 janvier 2021. URL: http:// journals.openedition.org/studifrancesi/9071 ; DOI: https://doi.org/10.4000/studifrancesi.9071

Questo documento è stato generato automaticamente il 13 janvier 2021.

\section{(c) (i) $\odot$}

Studi Francesi è distribuita con Licenza Creative Commons Attribuzione - Non commerciale - Non opere derivate 4.0 Internazionale. 


\title{
Marie-Claire Blais, L'esiliato seguito da I viaggiatori sacri
}

\author{
Veronica Cappellari
}

\section{NOTIZIA}

MARIE-CLAIRE BLAIS, L'esiliato seguito da I viaggiatori sacri, traduzione di Cristina MINELLE e Alessia TORMEN, cura e prefazione di Anne DE VAUCHER GRAVILI, Roma, Sinnos Editrice, 2007 , pp. 142.

1 Il recente volume L'Esiliato, seguito da I viaggiatori sacri, pubblicato dalla casa editrice Sinnos per la collana Laurentide, fa parte di un progetto di traduzione in italiano di opere brevi quebecchesi, finanziato e sostenuto dal CISQ (Centro Interuniversitario di Studi Quebecchesi) con la finalità di promuovere e diffondere la conoscenza di questa letteratura nel nostro paese. Esso raccoglie alcune novelle di Marie-Claire Blais, figura eclettica, ormai riconosciuta come una tra le più importanti scrittrici del panorama letterario quebecchese contemporaneo.

2 In questi racconti, l'autrice focalizza la sua attenzione su alcuni personaggi che ha personalmente incontrato nel corso della propria esistenza e dalle cui esperienze si è sentita particolarmente coinvolta, come emerge dal passo riportato da Anne De Vaucher Gravili nella prefazione: «[i] personaggi non smettono di occupare la nostra mente, perché più che personaggi sognati, sono personaggi che abbiamo conosciuto da vicino, nella realtà delle loro vite, li abbiamo captati, in tutta la loro umana spontaneità, come se, al contrario di noi, fossero destinati a non morire mai» (p. 7).

Nella raccolta di novelle - scritte in un arco di tempo di venticinque anni (1962-1989) è presente una variegata schiera di personaggi: nel Viaggio, un'adolescente intraprende un cammino metaforico verso la maturità che le consentirà di prendere coscienza delle diversità sociali di coloro che popolano il mondo di provincia in cui vive; in L'amica rivoluzionaria, invece, viene evocata Barbara Deming, nota scrittrice americana politicamente impegnata, negli anni Sessanta, nella strenua difesa della non-violenza e 
dei diritti delle donne e delle minoranze; e, infine, in Ai margini, il protagonista è un senzatetto che lotta per sopravvivere agli stenti nell'indifferenza di una grande metropoli nordamericana. Vittime di una società consumistica e corrotta, i protagonisti dell'opera narrativa blaisiana si collocano ai margini, osservatori attenti di un mondo che, rifiutandoli, li trasforma spesso in esseri invisibili.

4 Il libro si chiude con il poema-racconto I viaggiatori sacri - il cui titolo evoca la presenza, all'interno del testo, di luoghi di culto - nel quale è narrata la vicenda di tre giovani artisti (una scrittrice, un drammaturgo e un pianista), che formano un trio amoroso la cui storia avrà un tragico epilogo: due di essi annegheranno nella Senna, mentre il terzo morirà suicida.

5 Caratterizzati da una traduzione chiara ed aderente al testo, che ne consente, ad un pubblico straniero, un'agevole lettura, i diversi racconti sono un buon esempio della vivacità e delle variegata ricchezza della letteratura quebecchese degli ultimi decenni, che dà ampio spazio all'indagine della psiche umana, all'emotività, alle ansie e alle paure di un'epoca inquieta. 